\title{
Students Engaged in Collaborative Modeling
}

\author{
Peter Reimann, The University of Sydney, Faculty of Education, The University of Sydney NSW 2006, \\ p.reimann@edfac.usyd.edu.au \\ Anindito Aditomo, The University of Sydney, Faculty of Education, The University of Sydney NSW 2006, \\ aadi4954@mail.usyd.edu.au \\ Kate Thompson, The University of Sydney, Building A35, The University of Sydney NSW 2006, \\ k.thompson@edfac.usyd.edu.au
}

\begin{abstract}
The chat communication between students engaged in a collaborative modeling task, using a system dynamics modeling approach, was analysed. The analysis revealed a pattern to how students begin new problems in a chat and the analysis of the objects of learning identified issues with both communication between students and the design of one of the tasks. We describe a number of the emerging interactional practices and draw conclusions regarding the instructional use of modeling problems.
\end{abstract}

\section{Introduction}

This paper presents an in-depth qualitative analysis of three online groups learning about a system dynamic concept. Despite sourcing the materials from a well-known, well-resourced group (Maryland Virtual High School, 2001; Verona, Ragan, Shaffer, \& Trout, 2001), our previous analysis revealed that the three groups' online collaboration did not produce the necessary opportunities to achieve the anticipated learning outcomes (Reimann, Thompson, \& Aditomo, Submitted 31/10/2008). In this paper, we use an in-depth analysis informed by conversation analysis to examine the groups' interactional dynamics. This analysis seeks to reveal how the students' organised their interaction to render it meaningful (i.e. their meaning making practices), with the hope of gaining some insights into why the students did not achieve the anticipated learning outcomes. Consequences for both the design of the activity and moderation of the collaborative online learning environment are then discussed.

\section{Methods}

\section{Interaction analysis}

In conducting this analysis, we followed the methodological recommendations of Heritage (2005) and ten Have (1999). One researcher (the second author) read the transcripts to gain preliminary observations about the overall organisational structure of the conversations. Data sessions were then held with the other authors, who had also read the transcripts, to discuss the initial observations. After examining the transcripts' overall organisation, subsequent analysis focused on particular segments which were seen as interesting for the current purpose/context. This was followed by more detailed turn-by-turn analysis of certain sequences of the conversation.

\section{Participants and task context}

Using a synchronous chat-based tool, three groups were given 15 minutes to collaboratively address three questions, posted in the chat environment, about a simple model of deer population in a certain habitat. These questions were:

1. This model includes a carrying capacity. What are the implications of this for the behaviour of the model?

2. Change the birth rate and death rate in order to find a combination that will result in a decline in the deer population despite unlimited habitat.

3. In real life, there is a limit to the size of the available habitat. Choose a size of the habitat. What kind of growth does this illustrate? What is the carrying capacity of your habitat?

Students were required to download this model an external website, which contained not only the relevant model, but also a web-based simulation about the same phenomena (why this is important will become clear later).

The collaborative task focused on the "S-shaped" behaviour or growth, which is a basic pattern typical of many complex systems (Sterman, 2000). This pattern is produced by a system dynamic model which includes a "carrying capacity" which sets a limit to the growth of a population. In the model examined by the students, the deer's death rate was formulated as a function of the habitat's density (i.e. the death rate increases as the habitat becomes more populated). When density was low, death rate was lower than birth rate, giving an exponential population growth. However, as the population and density rises, the death rate also rises, which 


\section{STUDYING PRACTICES OF CSCL}

slows the population growth. When density reaches a certain point, the death rate will be equal to the birth rate and hence the population will stop growing or stabilises.

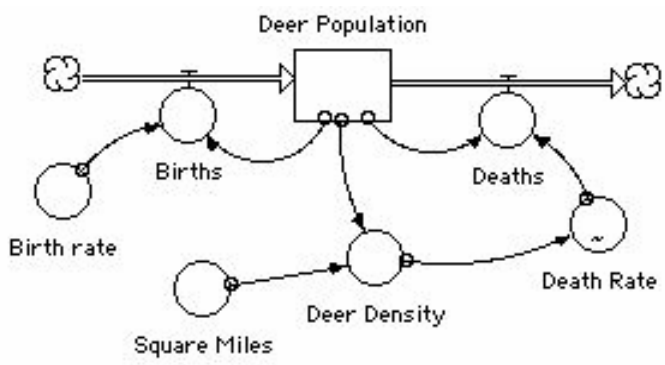

(a)

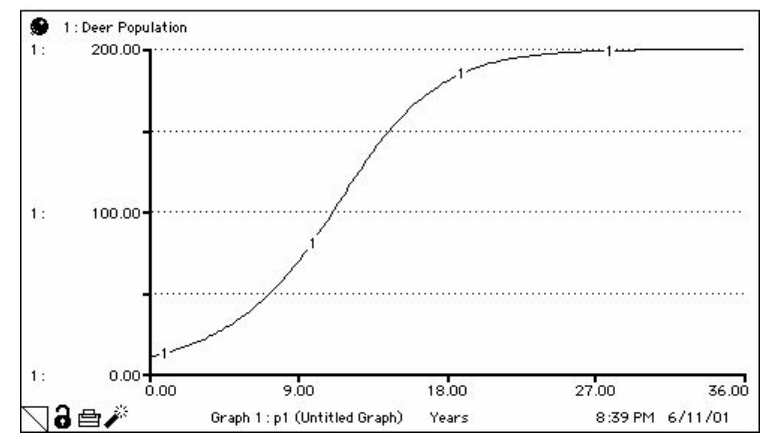

(b)

Figure 1: (a) The deer population model with a carrying capacity; (b) The S-shaped behaviour or growth pattern resulting from the model.

The task, in short, aims to help the students understand the relationship between the model structure (one which incorporates a carrying capacity) and the resulting behaviour or growth pattern (the S-shaped pattern).

\section{Results}

\section{Overall structural organisation of the chats}

Institutional interactions are often composed of certain phases which occur in a certain order (Heritage, 2005). (Casual conversations typically also have openings and endings, but what goes on in the middle are more unstructured compared to many institutional interactions.) Such overall structural organisation was also evident in the three groups' chat meetings, which exhibit roughly four phases:

1. Opening: Brief greetings

2. Establishment of interaction context: Remarks on group membership and/or tasks

3. Problem solving: Interaction addressing the problem or questions

4. Closing: Termination of chat meeting.

The purpose of outlining overall structural organisations is not to parse an interaction into discrete phases, or to demonstrate that those phases will occur in each interaction examined or that they will occur in a certain order. Rather, the purpose is to help analyse the activities that the participants were enacting through the interaction, and also how they oriented themselves towards this structural organisation (Heritage, 2005, p. 122).

\section{The organisation of the problem solving phase}

The analysis above has revealed the overall structural organisation of the chats. The analysis also shows how group members invoke aspects of their educational task or context to produce and structure their interaction. The problem solving phase will now be closely examined to determine how it is structurally organised.

The problem solving phase is structurally organised more or less along the questions which were posed by the tutor, although this is more evident in Groups 1 and 3, and less so in Group 2. That is, the group members discussed one question at a time, moving on when they had reached an answer perceived as adequate, or when someone invoked the time constraint as a reason to move on.

Table 1: An example from Group 1's discussion of the first question (Q1).

\begin{tabular}{|l|l|c|}
\hline Chat line number & Chat content & Context of interaction \\
\hline 36 & Stefan: i am back guys & \\
\hline 37 & Marjory: me too & \\
\hline 38 & $\begin{array}{l}\text { Emma: me too. have been trying to write a note about my } \\
\text { thoughts, but i can't get it to work. }\end{array}$ & $\begin{array}{l}\text { Beginning of Group } \\
\text { 1's discussion of Q1 }\end{array}$ \\
\hline 39 & $\begin{array}{l}\text { Stefan: so what we are supposed to do is to give a narritive } \\
\text { explanation to the model,right? }\end{array}$ & $\begin{array}{l}\text { Emma: This model includes carrying capacity, what are the } \\
\text { implications of this for the behaviour of the model? }\end{array}$ \\
\hline \multicolumn{1}{|c|}{ Lines 41 to 71 omitted } \\
\hline
\end{tabular}




\begin{tabular}{|l|l|c|}
\hline 72 & $\begin{array}{l}\text { Emma: although the more shelter there is, the more the deer } \\
\text { can hide. It's feasible that if there are too many deer, more } \\
\text { will be killed as they can't hide from predators. }\end{array}$ & \multirow{2}{|}{} \\
\hline 73 & Stefan: but the capicity is certain here & \multirow{2}{*}{ Time constraints } \\
\hline 74 & Stefan: only related to the square & \multirow{2}{*}{$\begin{array}{l}\text { End of Group 1's } \\
\text { discussion of Q1 }\end{array}$} \\
\hline 75 & Marjory: ok..why don't we move on to 2nd question? & \multirow{2}{*}{ Beginning of Group } \\
77 & Marjory: only 11 minuts left.. & 1's discussion of Q2 \\
\hline 78 & Stefan: yes & $\begin{array}{l}\text { Stefan: Change the birth rate and death rate in order to find a } \\
\text { combination that will result in a decline in the deer population } \\
\text { despite unlimited habitat (hint - this means that sq. miles must } \\
\text { be set to a REALLY LARGE value) }\end{array}$ \\
\hline
\end{tabular}

In the above (Table 1), Group 1's discussion of Q1 starts with line 39. This discussion was brought to an end by Marjory's reminder of their time limitation (Lines 75-76), to which Stefan conformed (Line 77). Stefan continued by posting a copy of Q2 (Line 78), effectively starting discussion of this second question. There was no objection to leaving Q1 and moving on to Q2, despite the unresolved difference between Emma and Stefan.

In Group 3, the discussion of Q1 started with Line 32 and ends with his Line 49 (Table 2). Different to Group 1, the discussion of Q1 in Group 3's chat was terminated not by reference to time constraints.

Table 2: Discussion of Question 1 in Group 3's chat.

\begin{tabular}{|c|c|c|}
\hline Chat line number & Chat content & Context of interaction \\
\hline 30 & Jane: i'll set the timer & \\
\hline 31 & $\begin{array}{l}\text { Ivan: I'm not sure what the first question mean. Are we } \\
\text { surpposed to explain the model? }\end{array}$ & $\begin{array}{l}\text { Discussion of Q1 } \\
\text { begins here for Group } \\
3\end{array}$ \\
\hline 32 & $\begin{array}{l}\text { Jane: the first question means how does the carrying capacity } \\
\text { of the area affect the model, i think }\end{array}$ & \\
\hline 33 & $\begin{array}{l}\text { Stewart: I think that is means the model needs to allow the } \\
\text { deer numbers be raised so the environment can handle it }\end{array}$ & \\
\hline 34 & $\begin{array}{l}\text { Stewart: In farming terms we have a carry capacity of so } \\
\text { many sheep per acre }\end{array}$ & \\
\hline 35 & Jane: yes, so there must be a limit to the number of deers & \\
\hline 36 & $\begin{array}{l}\text { Ivan: If the density of deer is over the carrying capacity of the } \\
\text { environment, then the death rate may rise? }\end{array}$ & \\
\hline 37 & $\begin{array}{l}\text { Stewart: So, if you have a carrying capacity of } 5 \text { sheep per } \\
\text { acre ... }\end{array}$ & \\
\hline 38 & Jane: yes because they wouldnt have enough food anymore & \\
\hline 39 & Jane: or something... & \\
\hline 40 & $\begin{array}{l}\text { Stewart: Correct If your farm is } 20 \text { acres there your maximum } \\
\text { number of sheep should not exceed what? }\end{array}$ & \\
\hline 41 & Jane: 100 & \\
\hline 42 & Ivan: 100 & \\
\hline 43 & Stewart: Correct & \\
\hline 44 & Ivan: yes & \\
\hline 45 & $\begin{array}{l}\text { Jane: and then the death rate increases and birth rate } \\
\text { decreases? }\end{array}$ & \\
\hline 46 & Ivan: I think so. & \\
\hline 47 & Ivan: then the density may go down to an appropriate level. & \\
\hline 48 & $\begin{array}{l}\text { Stewart: To keep the balance or carrying capacity correct I } \\
\text { suppose }\end{array}$ & \\
\hline 49 & $\begin{array}{l}\text { Ivan: I think we've mad e the answer to the first question } \\
\text { clear. Shall we go to Question } 2\end{array}$ & $\begin{array}{l}\text { Discussion of Q1 ends } \\
\text { here }\end{array}$ \\
\hline
\end{tabular}

In the interaction leading to the termination of Group 3's discussion of Q1, the group members built on each others' contributions to address Q1. In Line 45, Jane elaborated the group's previous discussion about the 
concept of "carrying capacity". This elaboration was formulated as a question (about the consequence of reaching a system's carrying capacity), thus demonstrating uncertainty and inviting an answer or correction. The other group members confirmed Jane's answer and elaborated it further. This co-elaboration was apparently read as adequate for the purpose of the task, because none objected when Ivan announced that they had answered Q1 and proposed to move on to Q2.

Based on this observation of the organisation of the problem solving phase, we can see that the students' overall orientation was towards an activity best described as "answering 3 questions in 15 minutes". This is to say that the chats were not oriented towards other activities which were also possible, such as "discussing concepts or ideas about complex systems" or "understanding system dynamic models". Had the chats been oriented towards these alternative activities, then we would expect to see the problem solving phases to be organised differently.

\section{How questions are addressed/answered}

Another interesting observation concerns how online groups address problems posed to them (see lines 31-33 in Table 2 above). Several observations can be made about Line 31, where Ivan proposed his interpretation of Q1. This line is composed of two parts, the first being prologue to the second, which contained Ivan's proposal or interpretation of Q1. The modifier "I'm not sure ..." in the first part conveys uncertainty and thus projects or anticipates possible rejection to the second part of this line (which was designed as a question, a further epistemic downgrading of this line). The first person inclusive pronoun ("Are we supposed to ...") indicates that this line addressed the group as a collective. Furthermore, by not specifying what is referred to by "the model", this line treats the group's knowledge of "the model" as unproblematic, at least at this stage.

The next two lines can be read as responses to Ivan's proposal. Again, in both lines "the model" was still treated as an unproblematic referent. In Line 32, Jane did not give an agreement to Ivan's question/proposal, but instead put forward her own proposal. Hence, this can be read as an indirect rejection of Ivan's proposal. It is interesting also that Jane ended her line with "..., I think". This modifies and epistemically downgrades her proposal, conveys uncertainty and projects possible rejection.

In Line 33, Stewart also proposed his own take on Q1, hence indirectly rejecting (or at least, not taking up or elaborating) Jane and Ivan's previous proposals. Compared to Ivan and Jane's proposals, Stewart's line here was not designed to convey the same degree of uncertainty. This reading is supported by the fact that Stewart, rather than waiting for a response from others, continued by elaborating his proposal:

Stewart's Line 34 was formulated as presentation of information, and the information (that farms have carrying capacity) was stated as a matter of fact. Jane concurred in Line 35 ("yes"), and continued by elaborating the meaning of Stewart's information to the deer population or model ("there must be a limit to the number of deers").

In the next line (36), Ivan posed a question about the relationship between carrying capacity and specific components of the model (density and death rate). By bringing up a different topic, Ivan was treating Stewart's informative sequence about the carrying capacity concept as complete or unnecessary to be continued. However, in Line 37, Stewart did not respond to Ivan's question, but continued his previous information sequence (as indicated also by the conjunction "so" at the beginning of this sentence). Furthermore, the ellipsis (three dots) in Stewart's line here signals an unfinished turn. In effect, at this point of the discussion, two simultaneous streams of conversation have appeared.

Jane, in Lines 38 and 39, answered Ivan's question (and not to Stewart). Jane's answer was formulated as an elaborated confirmation ("yes because ..."). This answer, however, also conveyed uncertainty, as indicated the modifier "or something", which can be read as inviting further elaboration of the topic Ivan brought up (carrying capacity and death rate). Stewart, however, responded not with an elaboration of this, but with an evaluation ("correct") which effectively closes Ivan and Jane's exchange by incorporating it into his own informative sequence. Indeed, Stewart used the same turn to continue his informative sequence.

At this point, Stewart's informative sequence resembles what previous researchers call an IRE (initiation-response-evaluation) sequence typical of teacher centred classroom interaction. Thus, Stewart's question in Line 40 was treated not as genuinely seeking information, but akin to a teacher's "test" question. This can be seen from Jane and Ivan's response (both giving Stewart the answer he wanted: "100" sheep). And Stewart closed this IRE sequence with a short evaluation in Line 43 ("Correct").

With the completion of Stewart's IRE sequence, in Line 45 Jane tries to link the discussion of carrying capacity (with the conjunction "and") to specific components of the model (death and birth rate). Ivan responds by elaborating his opinion on the consequence (of reaching carrying capacity) to the "density" (which is another component of the model not mentioned before). Interestingly, in Line 48, Stewart pulls the focus back to "carrying capacity".

Thus, it seems that whereas Jane and Ivan focused on the relationship between carrying capacity and specific components of the model, Stewart focused solely on the carrying capacity concept. This difference in focus was resolved interactionally, but not acknowledged or brought into explicit discussion by the group. 
Instead, the act of co-elaboration which involved all members was taken as an adequate response to Q1. So when Ivan made an assessment (that they had answered Q1), none objected.

\section{Conclusions and discussion}

The interactions were organised along the constraints imposed by the task description (educational context, three problems, and time limitations). This organisation of the interaction might reflect a "satisficing" approach, in which the students were merely satisfying the formal requirements of the task (addressing 3 questions, with less concern over achieving shared understanding of the topic/phenomenon). One interactional practice which was regularly used was that of "uncertainty display". This was used to start the discussion of a new problem (this was observed in all instances from all 3 groups). Uncertainty display was most commonly performed by formulating the initial turn (with regard to a question or problem posed by the task) as a question, which invites others to confirm or to propose their own interpretations on the problem.

The practical recommendations of this analysis concern both the facilitation of the online groups and the design of the task. The identification of the four phases around which students' discussions were based suggests that more time should be given to allow enough time to complete the important problem-solving phase. This suggestion is supported by the time constraints that students used to decide that they should move on to the following question before completely understanding the first. As mentioned earlier in this paper, students did not attain the learning outcomes expected from this task. A combination of this analysis, with that examining the opportunities for learning (see (Reimann et al., Submitted 31/10/2008)) give some suggestions for the misunderstandings held by students. Further research needs to be conducted using similar analyses on a revised activity to determine whether these misconceptions about system dynamics models are due to the design of the task, or the difficulties identified by other authors in understanding this type of model (e.g. (Moxnes, 2004)). These initial results certainly suggest that the design of the task plays a large role in students' ability to understand these concepts.

\section{References}

Heritage, J. (2005). Conversation analysis and institutional talk. In K. L. Fitch \& R. E. Sanders (Eds.), Handbook of Language and Social Interaction (pp. 103-147): Routledge.

Maryland Virtual High School. (2001). CoreModels Final Report (9707702) Findings. Retrieved 08/11/07, from http://mvhs.shodor.org/coremodels/cmindex.html

Moxnes, E. (2004). Misperceptions of basic dynamics: the case of renewable resource management. System Dynamics Review, 20(2), 139-162.

Reimann, P., Thompson, K., \& Aditomo, A. (Submitted 31/10/2008). Use of conversation analysis and variation theory to assess an online collaborative task using system dynamics models. Paper presented at the Fostering Communities of Learners, EARLI 2009, Amsterdam, the Netherlands.

Sterman, J. D. (2000). Business Dynamics. Systems Thinking and Modeling for a Complex World.: McGrawHill Higher Education.

ten Have, P. (1999). Doing Conversation Analysis. Londong: Sage Publications.

Verona, M. E., Ragan, S., Shaffer, D., \& Trout, C. (2001). Working paper: A case study of materials development fostered by the MVHS CoreModels Project. Retrieved 18/4/05, from mvhs1.mbhs.edu/mvhsproj/workmatdev.pdf 